Case Report

\title{
GUILLAIN-BARRÉ SYNDROME ASSOCIATED WITH ACUTE HEV HEPATITIS
}

\author{
Rawshan Ara Khanam, Mohammad Omar Faruq, Rawshan Ali Basunia, ASM Areef Ahsan \\ Department of Critical Care Medicine (ICU), Ibrahim Medical College \& BIRDEM
}

\begin{abstract}
Guillain-Barré Syndrome (GBS) otherwise known as Acute Inflammatory Polyneuritis, characterized by acute progressive limb weakness and aretlexia, is the prototype of a post infectious autoimmune disease. Two-thirds of the cases of GBS emerge from viral or bacterial infection. In August 2006, a 20 year old man presented at ICU, BIRDEM Hospital with a history of brief icteric illness followed by progressive bilateral symmetrical hypotonic aretlexic muscular weakness, bilateral infra-nuclear facial palsy and bulbar weakness. Later on, he was diagnosed as a case of GBS and acute hepatitis E. Up till now, only three cases of GBS associated with hepatitis E have been reported in the medical literature world wide. This is probably the $4^{\text {th }}$ case to be reported.
\end{abstract}

Ibrahim Med. Coll. J. 2008; 2(1): 32-34

Indexing words: Guillain-Barré Syndrome, acute hepatitis E

\section{Introduction}

The incidence of the typical GBS has been reported to be relatively uniform between 0.6 and 4 cases per 100 000 per year thought-out the world ${ }^{1}$. In two thirds of cases there are occurrences of gastroenteritis or flu like illness within six weeks of onset of $\mathrm{GBS}^{2-3}$. Campylobacter jejuni is reported to be the most frequent antecedent pathogen followed by cytomegalovirus $^{4}$. Association of GBS with viral hepatitis is well documented. Most of the reported associations are with acute hepatitis $\mathrm{B}^{5-6}$ and hepatitis $\mathrm{A}^{7}$. Few cases also have been reported with Hepatitis $\mathrm{C}^{8}$. Association of GBS with HEV hepatitis is rare. Only three such cases have been published so far ${ }^{9-11}$.

\section{Case Report}

In August 2006, a Bangladeshi 20 year old man employed in a plastic factory was admitted in the ICU, BIRDEM with the complaints of jaundice, weakness of limbs and dyspnoea. About fifteen days prior to admission (PTA), he developed low grade fever, anorexia, nausea and vomiting. Seven days PTA he noticed yellowish discoloration of skin, sclera, and urine. Five days PTA, he felt weakness of both lower limbs progressing to both upper limbs over the next two days. He had no bladder or bowel dysfunction. Three days PTA, he developed dysphagia to both solid and liquid food accompanied by respiratory distress. Then he got admitted in an ICU out side of BIRDEM. There he was intubated and kept on mechanical ventilation (MV) and was finally transferred to ICU, BIRDEM. The patient had no prior history of receiving vaccination with in few months PTA.

On admission, he was conscious and mildly icteric. Respiratory rate was $24 / \mathrm{min}$, pulse $100 / \mathrm{min}$, blood pressure $150 / 80 \mathrm{~mm}$ of $\mathrm{Hg}$ and temperature $99^{\circ} \mathrm{F}$. Systemic examination revealed mild tenderness in right hypochondrium and soft enlarged tender liver about 2 $\mathrm{cm}$ from the right costal margin. Neurological examination showed bilateral lower motor neuron (LMN) type facial palsy with evidence of dysphagia. Muscle power was $2 / 5$ in all four limbs with diminished muscle tone. All the deep tendon and superficial reflexes were absent. Planter responses were equivocal. All sensory functions including touch, temperature and vibration were intact and there was no sign of meningeal irritation.

\footnotetext{
Address for Correspondence:

Prof. Rawshan Ara Khanam, Department of Internal Medicine, Ibrahim Medical College \& BIRDEM

122 Kazi Nazrul Islam Avenue, Shahbag, Dhaka-1000
} 
Laboratory investigations showed a total WBC count of $18700 / \mathrm{cmm}$ with Poly- $85 \%$, Lympho- $12 \%$, Mono$02 \%$ and Eosin- $01 \%$. Serum billirubin was $3.6 \mathrm{mg} / \mathrm{dl}$, ALT-2509U/L, AST-290 U/L, and Alkaline Phosphatase $-580 \mathrm{U} / \mathrm{L}$, with normal levels of urea, creatinine, electrolyte and coagulation profile. His anti HEV IgM was positive (ELISA, sample OD 2.735, cut off value 0.328 ) with negative viral markers for hepatitis B, hepatitis $\mathrm{C}$ and hepatitis A.

Ultrasonography revealed hepatomegaly suggestive of acute hepatitis. Nerve conduction studies revealed both demyelinating and axonopathic sensory motor polyneuropathy. CSF study showed albumin $190 \mathrm{mg} / \mathrm{dl}$ with " 0 " cell count - suggestive of albuminocytologic dissociation.

After diagnosis, the patient was advised for immunomodulation by either intravenous immunoglobulin (IvIg) or plasmapheresis. Although advised, patient could not be given IvIg or plasmapheresis for financial constraints. However, his muscle power showed significant improvement within one week of admission and reached $4 / 5$ at lower limbs and 3/5 at upper limbs by two weeks of admission. Patient was successfully extubated from MV seven days after admission.

\section{Discussion}

GBS is a disease of peripheral nervous system, which is caused by aberrant immune response, directed against some components of peripheral nerves ${ }^{12}$. The targeted antigens may be gangliosides present on plasma membrane of cell (e.g. GM-1, GD-1a), Swchawnn cell neurons (nerve growth cone region). There are four common sub types based on clinical and neuro-physiological studies e.g. 1. Acute Inflammatory Demyelinating Polyneuropathy (AIDP), 2. Acute Motor Axonal Neuropathy (AMAN), 3. Acute Motor Sensory Axonal Neuropathy (AMSAN), 4. Millar Fisher's Syndrome ${ }^{13}$.

Established diagnostic criteria exists. Once the clinical diagnosis is made, sub type classification can be done by using neuro-physiological study. Such study also confirms that the disease is a peripheral neuropathy ${ }^{14-15}$. Nerve conduction study in this case was suggestive of AMSAN subtype.

In rare cases, where nerve conduction studies cannot be done because of lack of recordable action potential, nerve biopsy can differentiate the subtypes. However this is done only for research purposes ${ }^{16-17}$. CSF studies shows raised protein and paucity of cell in $80 \%$ cases (albuminocytologic dissociation), in $20 \%$ cases CSF study is usually normal in first few days of illness ${ }^{18-19}$. In this case, albuminocytologic dissociation was present when the CSF was studied four days after admission.

The treatment of GBS is multidisciplinary. Both plasma exchange and high dose of immunoglobulin are effective in reducing both the severity of the disease and the neurological deficits. Steroids are not effective in $\mathrm{GBS}^{20}$. A randomized controlled trial showed that IvIg has similar efficacy to plasma exchange and it is recommended as the first line of treatment for severe GBS in most hospitals because of its greater convenience $^{21}$. There are also case reports of spontaneous recovery of GBS without IvIg or plasmapheresis ${ }^{22}$. One of the three reported cases with $\mathrm{HEV}^{9}$ as well as this case recovered spontaneously without Immunomodulation.

\section{References}

1. Hubhcs RAC, Rees JH. Clinical and epidemiological features of Guillain-Barré Syndrome. J Infect Dis 1997; 176(suppl): S92-98.

2. Winer JB, Hughes RAC, Anderson MJ, Jones DM, Kangro H, Watkin RFP. A prospective study of acute idiopathic neuropathy. J Neurol Neurosur Psychiatry 1988; 51: 613-18.

3. Guillain- Barré Syndrome study group. Guillain-Barré Syndrome: an Italian multicentre case control study. Neurol Sci 2000; 21: 229-34.

4. Schmidt-Ott R, Schmidt H, Feldmann S, Brass F, Krone B, Gross U. Clin Vaccine Immunol 2006; 13(7): 77983.

5. Berger JR, Ayyar R, Sharemata WA. Guillain-Barré Syndrome complicating acute hepatitis B. A case with detailed electrophysiological and immunological studies. Arch Neurol 1981; 38: 366-8.

6. Ray G, Ghosh B, Bhattacharya R. Acute hepatitis B presenting as Guillain-Barré Syndrome. Indian $J$ Gastroenterol 2003; 22(6): 228.

7. Chitamber SD. Fadnis RS, Joshi MS, Habbu A, Bhatia SG. J Med Virol 2006; 78(8): 1011-4.

8. Lacaillc F, Zvlberberg H, Hagege H, Roualdes B, Meyrignac C, Chousterman M, Girot R. Hepatitis C associated with Guillain-Barré Syndrome. Liver 1998; 18(1): 49-51. 
9. Sood A, Midha V, Sood N, Guillain-Barré Syndrome with Acute Hepatitis E. AM J Gastroenterol 2000; 95(12): 3667-8.

10. Rajesh K, Bhoi S, Manish K, Sharma B, Singh BM, Gupta BB. Guillain-Barré Syndrome with Acute Hepatitis E - a rare association. J Indian Acad Clin Med 2002; 3: $389-91$.

11. Kamani P, Baijal R, Amarapurkar D, Gupte P, Patel N, Kumar PH, Agal S. Guillain-Barré Syndrome associated with Acute Hepatitis E. Indian J Gastroenterol 2005; 24: 216.

12. Palazzuoli A, Lenzi C, Iovine F, Carrea A, Nuti R. Neurol Sci 2006; 26(6): 447-50.

13. Rchard AC Hughes, David R Cornblath, Lancet 2005; 336: $1653-66$.

14. Hadden RDM, Cornblath DR, Hughes RAC. et al. Electrophysiological classification of Guillain-Barré Syndrome: Clinical association and outome. Ann Neurol 1998; 44: 780-88.

15. Ho TW, Mishu B Li CY, et al. Guillain-Barré Syndrome in northern China. Relationship to campylobacter jejuni infection and anti glycolipid antibodies. Brain 1995; 118: 597-605.
16. Hall SM, Hughes RAC, Payan J, Atkinson PF, McColl I, Gale A. Motor nerve biopsy in severe Guillain-Barré Syndrome. Ann Neurol 1992; 31: 441-44.

17. Barciano J, Figols J, Garcia A, et al. Fulminant GuillainBarré Syndrome with universal excitability of peripheral nerves. A clinicopathological study. Muscle Nerve 1997; 20: 846-57.

18. Paradiso G, Tripoli I, Galicchio S, Fejeman N. Epidemiological, clinical and electro diagnostic findings in childhood Guillain-Barré Syndrome. A reappraisal. Ann Neurol 1999; 46: 701-07.

19. Hughcs RAC. Guillain-Barré Syndrome. Heidelberg: springerverlag; 1990.

20. Cosi V, Versino M. Guillain-Barré Syndrome. Neurol Sci 2006; 27(suppl 1): 347.

21. Van der Mechc FGA, Schmitz PIM, Dutch. GuillainBarre Study group. A randomized trial comparing intravenous immunoglobulin and plasma exchange in Guillain-Barre Syndrome, N Engl J Med 1992; 326: 1123-29.

22. Lundkvist I, Van Doorn PA, Vermeulen M, Brand A. Guillain-Barré Svndrome, spontaneous recovery. Clin Immunol Immunopathol 1993; 67(3 pt 1): 192-8. 